\title{
Correction to: Inspiring Life in Frozen Communities: Supporting Migrant Women in Brussels to Regain Control over their Lives
}

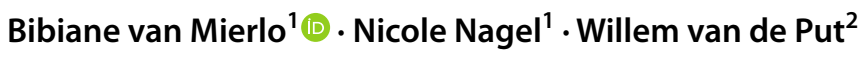

Published online: 2 December 2020

(c) Springer Science+Business Media, LLC, part of Springer Nature 2020

Correction to: Community Mental Health Journal https://doi.org/10.1007/s10597-020-00743-z

The original version of this article unfortunately contained an error in Affiliation section.

Bibiane van Mierlo and Nicole Nagel are affiliated to Culture4Change, Utrecht, The Netherlands and Willem van de Put is affiliated to Department of Public Health, Institute of Tropical Medicine, Antwerp, Belgium.

The original article has been corrected.

Publisher's Note Springer Nature remains neutral with regard to jurisdictional claims in published maps and institutional affiliations.

The original article can be found online at https://doi.org/10.1007/ s10597-020-00743-z.

Bibiane van Mierlo

bibiane.vanmierlo@culture4change.com

Nicole Nagel

nn@rolfing-stimme.de

Willem van de Put

wvandeput@itg.be

1 Culture4Change, Utrecht, The Netherlands

2 Department of Public Health, Institute of Tropical Medicine, Antwerp, Belgium 